\title{
Regional Characteristics of Recent Dust Occurrence and Its Controlling Factors in East Asia
}

\author{
Jing $\mathrm{Wu}^{1}$, Yasunori Kurosaki ${ }^{2}$, Masato Shinoda ${ }^{1}$, and Kenji Kai ${ }^{1}$ \\ ${ }^{1}$ Graduate School of Environmental Studies, Nagoya University, Nagoya, Japan \\ ${ }^{2}$ Arid Land Research Center, Tottori University, Tottori, Japan
}

\begin{abstract}
Aeolian dust, resulting from wind erosion, is controlled by two major factors: aeolian erosivity (i.e., wind speed) and aeolian erodibility (i.e., land surface conditions). Erodibility factors include a number of land surface parameters that interact in complicated manners. Thus far, the extent to which each of the factors contributes to dust outbreaks, which vary regionally and seasonally, remains unclear. As such, we present a novel map of the controlling factors for dust outbreaks in dryland of East Asia by quantifying the relative contributions of the erosivity and various erodibility parameters to inter-annual dust variations on a station basis during the period of 1999 to 2013. Erosivity controls dust outbreaks in the Taklimakan Desert, west of the Hexi Corridor, and on the north side of the Altai Mountain. On the other hand, dust outbreaks are dependent on erodibility in steppe regions: lower precipitation or less abundant vegetation during the previous summer was found to be related to dusty springs in the Mongolian steppe, whereas the less abundant spring vegetation and reduced snow cover enhanced dust outbreaks in the Inner Mongolian steppe. Anthropogenically restored vegetation in desertified areas was found to be likely to suppress dust outbreaks in the Loess Plateau.
\end{abstract}

(Citation: Wu, J., Y. Kurosaki, M. Shinoda, and K. Kai, 2016: Regional characteristics of recent dust occurrence and its controlling factors in East Asia. SOLA, 12, 187-191, doi:10.2151/sola. 2016-038.)

\section{Introduction}

Aeolian dust has a number of environmental effects, for example, on air pollution, on the health of humans and livestock, and on the climate (Miller and Tegen 1998; Wang et al. 2005). Many global models have been developed in order to simulate a series of processes, namely, dust emission, transport, and deposition (e.g., Ginoux et al. 2001; Woodage et al. 2010). Due to a lack of observational evidence of land surface characteristics as well as a lack of understandings of how these characteristics impact dust emission, uncertainties remain in simulating dust emission processes (e.g., Uno et al. 2006; Todd et al. 2008).

Aeolian dust, resulting from wind erosion, is dependent on aeolian erosivity (hereinafter, erosivity) and aeolian erodibility (hereinafter, erodibility) (UNEP 1997). Erosivity is the ability of wind forces to erode existing soil and is controlled primarily by wind strength. The erosivity factor is simply expressed by wind speed, and its relation to dust outbreaks has been widely studied (e.g., Kurosaki and Mikami 2003). The significant effect of strong wind on dust outbreaks in desert regions has been reported (Kim and Kai 2007). Strong wind, which is the driving force to cause dust storms, is majorly formed by synoptic scale cyclones around the Gobi Desert (e.g., Takemi and Seino 2005), and is majorly formed by gravity current associated with mesoscale cold front in the Taklimakan Desert (e.g., Aoki et al. 2005).

Erodibility is the susceptibility of soil and land surface to wind erosion, which, with some exceptions, has not been well measured

Corresponding author: Jing Wu, Nagoya University, D2-2(510), Furo-cho, Chikusa-ku, Nagoya 464-0801, Japan. E-mail: wu.jing@d.mbox.nagoya-u. ac.jp. (C)2016, the Meteorological Society of Japan. or quantified over a broad area (Kurosaki and Mikami 2007; Kurosaki et al. 2011b). Erodibility is influenced by various factors, such as vegetation coverage, snow cover, and soil moisture. These factors are characterized by substantial seasonal, inter-annual and spatial variations. In general, spring is dust season in East Asia, although seasonal changes are strongly controlled by drastic changes in land surface conditions. For example, in spring, frozen ground increased the threshold wind speed for dust outbreaks in the East Mongolian Plateau (Han et al. 2011). Abulaiti et al. (2014) pointed out that the freeze-thaw cycle during spring resulted in a lower threshold wind speed for dust outbreaks on the desert steppe of Mongolia, whereas Ishizuka et al. (2012) suggested that the destruction of the crust on the surface in the spring reduced the threshold wind speed at the same site. As for the inter-annual variations of dust outbreaks, Zou and Zhai (2004) and Liu et al. (2004) demonstrated that abundant spring vegetation resulted in a decline in dust frequency in Inner Mongolia during the period of 1982 to 2001. Lee and Kim (2012) revealed that the occurrence of dust outbreaks was reduced by spring snow coverage in Inner Mongolia and the Gobi Desert, and by spring vegetation in the Loess Plateau during the period of 1996 to 2007. The land surface memory in the Mongolian grasslands was investigated by Shinoda and Nandiatsetseg (2011). They showed that soil moisture and vegetation anomalies determined by summer precipitation were maintained during winter, affecting dust occurrence in the following spring. Nandiatsetseg and Shinoda (2015) also pointed out that standing dead grasses had the most significant impact on spring dust outbreaks. Kurosaki and Mikami (2007) reported the spatial distributions of the threshold wind speed, which can be used as an index of erodibility. The threshold wind speed was the lowest in the Taklimakan Desert, and the highest in northern Mongolia.

Given the above-mentioned background, substantial temporal and spatial variations in erosivity and erodibility in East Asia should be related to those of dust outbreaks through a systematic analysis of the entire area. Kurosaki et al. (2011a) suggested that changes in erodibility parameters of precipitation, soil moisture, and above-ground biomass significantly influenced dust outbreaks in April by using data at only one station for Mandalgobi, Mongolia. However, wider identification of the controlling factors for dust outbreaks has not been conducted over the entire arid and semi-arid region in East Asia.

In the present study, we investigate inter-annual variations (1999-2013) of spring dust outbreaks as well as erosivity and erodibility over arid and semi-arid regions in East Asia. We herein present a novel map of the controlling factors for dust outbreaks by identifying the relative contributions of erosivity and erodibility factors to recent inter-annual variations in dust occurrence on a station basis.

\section{Data and study method}

\subsection{Meteorological data}

The region of interest in the present study and SYNOP observatories are shown in Fig. 1. The land cover type of the study region is generally divided to desert, desert steppe, and steppe referring to the map given by Qi et al. (2012). Data for dust outbreaks, wind speed and precipitation were extracted from 6-hourly SYNOP reports during the period from 1999 to 2013 (World Meteorological Organization 1995). Similar to Kurosaki et al. (2003), dust outbreaks are defined by the classification of present 


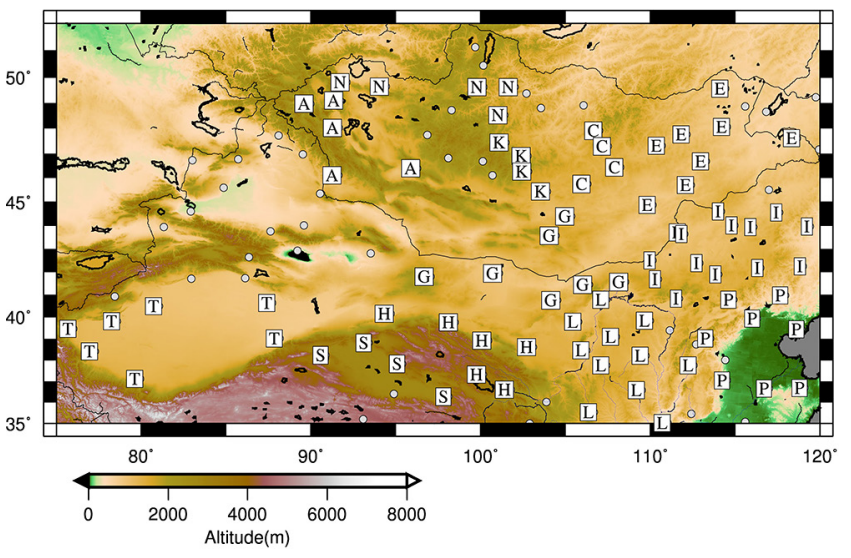

Fig. 1. Topography and distribution of SYNOP observation sites (dots and squares). Stations used in the present analysis are indicated by squares. An alphabet in a square indicates the region name; "A" (Altai Mountain), "N" (Northern Mongolia), "K" (Khangai Mountain), "C" (Central Mongolia), "E” (Eastern Mongolia), "G" (Gobi Desert), "T" (Taklimakan Desert), "S" (Tsaidam), "H" (Hexi Corridor), "L" (Loess Plateau), "I" (Inner Mongolia). Background color indicates altitude.

weather codes: containing blowing dust $(\mathrm{ww}=07,08)$ and dust storm $(\mathrm{ww}=09,30-35,98)$.

In the present study, we defined strong wind as wind speeds greater than $6.5 \mathrm{~m} \mathrm{~s}^{-1}$, which is used as a threshold value for dust emission in the arid and semi-arid regions in many studies (e.g., Tegen and Fung 1995). The dust outbreak frequency (DOF) is defined as the ratio of the number with dust outbreaks to the total number of observation days during a given period, and the strong wind frequency (SWF) is similarly expressed as the ratio of the number of days with strong wind to the total number of observation days during a given period. Both the DOF and SWF are expressed as percentages.

Lee and Kim (2012) and Kurosaki and Mikami (2005) demonstrated that the DOF peaks yearly in April. In order to focus on the most frequent dust occurrence, we compiled the average DOF in April at each station. We excluded SYNOP stations for which the average number of dust outbreaks was less than one day per year. Analysis was conducted at the remaining 66 SYNOP stations (squares in Fig. 1).

Precipitation during the summer contributes to more than half of the annual precipitation amount and greatly contributes to the soil moisture and vegetation growth. Therefore, we used the accumulated amount of precipitation from June to August (P) as the precipitation amount for the growing season of vegetation. The total summer precipitation from 1998 to 2012 was used here, because the residues (i.e., dead leaves) of grown vegetation resulting from precipitation during the previous summer are expected to affect dust outbreaks in the following spring.

\subsection{Land surface condition}

We investigated the normalized difference vegetation index (NDVI) and snow coverage in the present study. The NDVI data were derived from SPOT-vegetation 10-days composite dataset with $1 \mathrm{~km}$ resolution (http://free.vgt.vito.be/). We used the monthly average NDVI in April (A) and the annual maximum NDVI (M) of the previous year.

Snow coverage data were compiled from MODIS/Terra Snow Cover Monthly L3 Global 0.05Deg CMG, Version 5 (Hall and Salomonson 2006). This dataset was released in 2000, we used the monthly percentage of snow in March and April (S), 2000-2013. In the present study, we made a spatial approximately $50 \mathrm{~km} \times$ $50 \mathrm{~km}$ average for NDVI and snow cover data for each station.

\subsection{Dust outbreak ratio}

In the present study, we used dust outbreak ratio (DOR) as an index of erodibility. The DOR is defined as the ratio of the DOF to the SWF. Normalized by strong wind, the index indicates the possibility of dust occurrence for a given wind condition. The DOR expresses the vulnerability of the land surface condition to wind erosion. A high DOR indicates a vulnerable land surface, for which dust outbreaks tend to occur. Kimura and Shinoda (2010) and Kurosaki et al. (2011a) used the same definition for the DOR, but they used different definition for the SWF.

\section{Results and discussion}

\subsection{Dust occurrence}

Figure 2 shows the spatial distribution of the DOF during the study period of 1999 to 2013. Generally, dust outbreaks occurred more frequently in Mongolia than in northern China. The highest DOF was recorded in the Gobi Desert, coinciding with one of the major dust sources from March 1988 to May 2004 (Kurosaki and Mikami 2005). Tsogt-Ovoo $\left(105.31^{\circ} \mathrm{E}, 44.42^{\circ} \mathrm{N}\right)$, located in the Mongolian Gobi Desert, had the highest number of dust outbreaks (i.e., 138).

Dust outbreaks were also frequently observed in the Altai Mountain region. A high dust storm frequency was reported at the southern side of the Altai Mountain during the period from 1937 to 1999 by Natsagdorj et al. (2003). This region, which has a desert-steppe land cover type, has been a dust source region in recent decades.

A high DOF was also found in the Mongolian steppes. Being sensitive to climate change and intense human disturbances (e.g., grazing), the Mongolian steppes appear to act as potential dust sources (Shinoda et al. 2011).

\subsection{Controlling factor}

In order to identify the most significant controlling factor to the DOF, we classified the stations into five categories in terms of relative contributions of erosivity and erodibility to the inter-annual variations: erosivity only, erosivity > erodibility, erosivity < erodibility, erodibility only, and unclassified.

The DOF was regressed, on a station basis, on the SWF and the DOR using a linear regression model. If the DOF was significantly related to only the SWF (or DOR) at the 5\% significance level $(\mathrm{p}<0.05)$, such stations were classified as erosivity (or erodibility) only. If the DOF was significantly related to both the SWF and the DOR, out of the two, a larger value of the correlation coefficient indicates a greater contribution. Such stations were classified as erosivity $>$ (or $<$ ) erodibility. Regression curves and the correlations between the DOR and the erodibility parameters of A, M, P and S (see Sections 2.1, 2.2 and 2.3) were derived at the $5 \%$ and $10 \%$ significance levels for each station, where the DOF was more strongly related to the DOR. Figures 3 and 4 show an example at Choir $\left(108.21^{\circ} \mathrm{E}, 46.45^{\circ} \mathrm{N}\right)$, Mongolia. The DOF increased with an increase in the DOR. The SWF varied considerably from year to year before 2006 and exhibited a peak value in

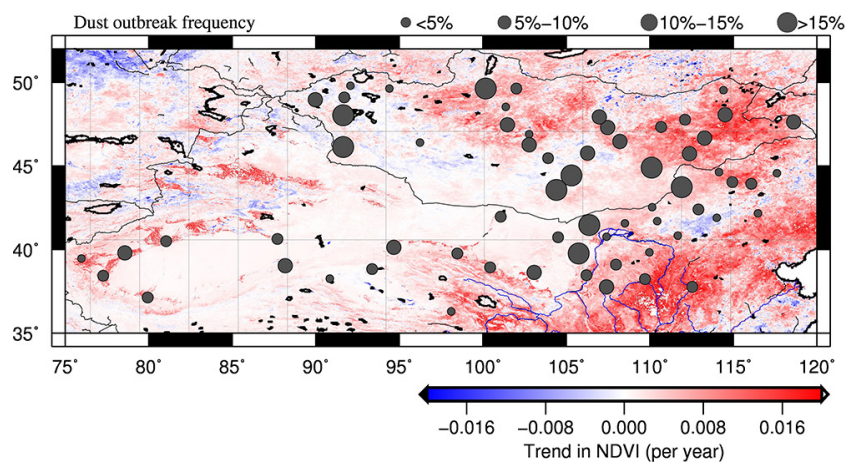

Fig. 2. Spatial distribution of the average DOF in April from 1999 to 2013. The sizes of the circles indicate the DOFs that were grouped in $<5 \%$, $5-10 \%, 10-15 \%$ and $15 \%$, respectively. Background color indicates the changing trend of summer NDVI from 2000 to 2012. 

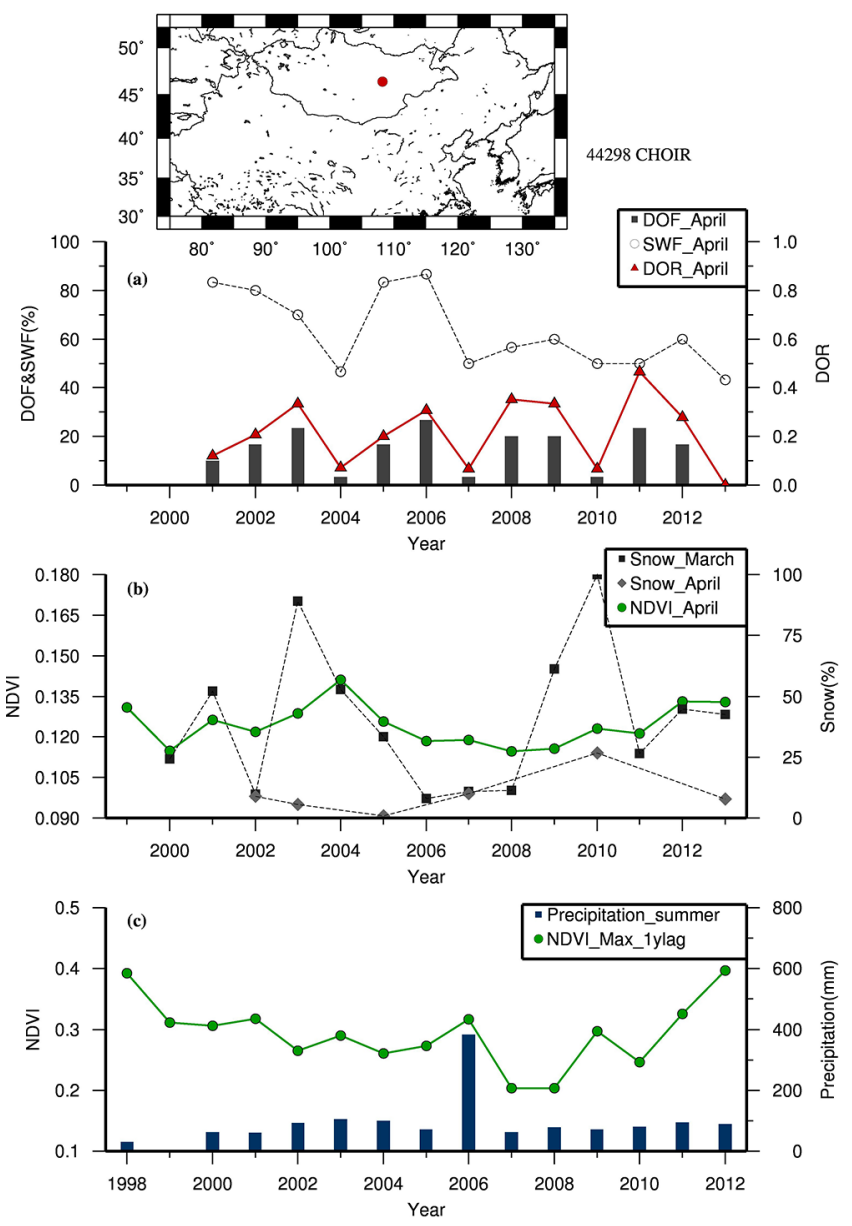

Fig. 3. Inter-annual variations of (a) DOF, SWF, DOR in April, (b) NDVI in April and snow coverage in March and April during the period 19992013 and (c) summer precipitation (June to August) and annual maximum NDVI during the period 1998-2012 at Choir, Mongolia.
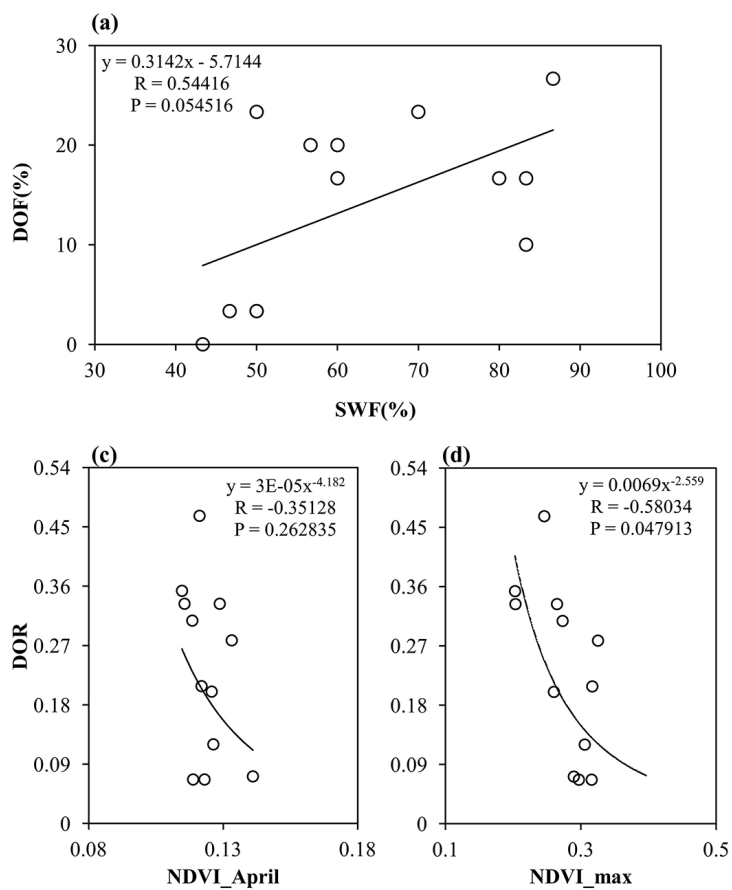

2006, resulting in the highest DOF. The NDVI was in the range of 0.1 to 0.15 in April and in the range of 0.2 to 0.4 in summer. The snow cover was higher in March than in April. The total amount of summer precipitation was approximately $100 \mathrm{~mm}$, except for 2006. Figure 4 shows that the DOF at Choir was related to the combined impact of erosivity and erodibility, whereas the contribution of the DOR $\left(r^{2}=0.86, p<0.00001\right)$ was greater than that of the SWF $\left(r^{2}=0.30, p=0.05\right)$. As for the erodibility parameters, the most significant factor was $\mathrm{M}\left(\mathrm{r}^{2}=0.35, \mathrm{p}<0.05\right)$.

Those stations with the identified controlling factor revealed regional characteristics. A map of the spatial patterns of factors that had a controlling impact on dust occurrence is shown in Fig. 5.

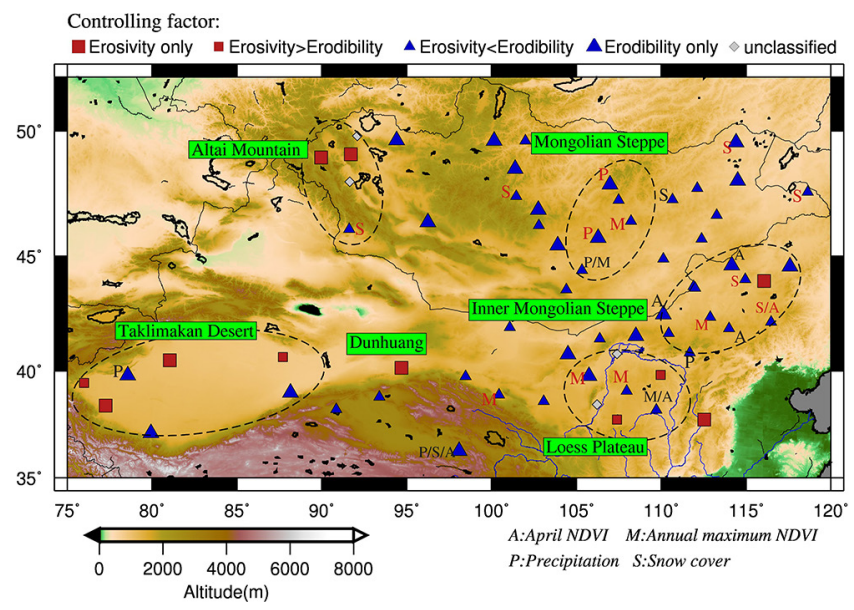

Fig. 5. Map of the controlling factors for dust emission in East Asia. The stations, where erosivity shows statistically significant correlation with the DOF at $5 \%$ confidence level are shown in red squares. The stations, where erodibility shows a stronger correlation with the DOF are shown in blue triangles. The stations, where snow cover on March, NDVI on April, annual maximum NDVI in the previous year and precipitation amount for June to August in the previous year controls DOR, are shown by "S", "A", "M", or "P", respectively at 5\% (red) and 10\% (black) confidence level. Background color illustrates altitude.
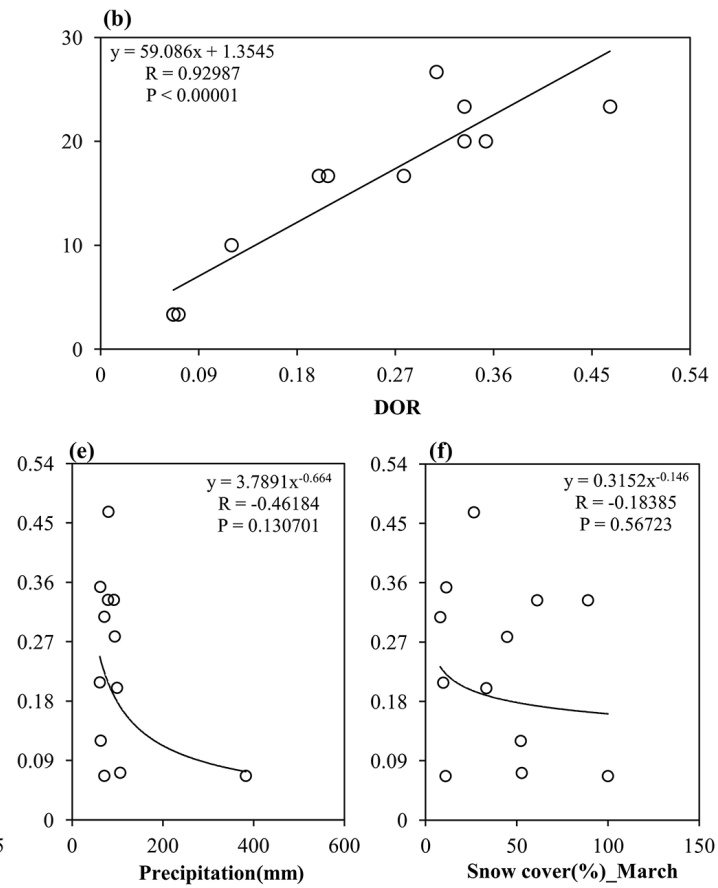

Fig. 4. Scatter diagrams for (a) DOF and SWF, (b) DOF and DOR in April 1999-2013; DOR and (c) NDVI in April, (d) annual maximum NDVI and (e) summer precipitation (June to August) in the previous year, and (f) snow cover in March at Choir, Mongolia. 


\section{a. Desert and desert-steppe region}

Strong wind is significantly positively correlated with dust outbreaks at most stations in the Taklimakan Desert, west of the Hexi Corridor (Dunhuang, $94.67^{\circ} \mathrm{E}, 40.15^{\circ} \mathrm{N}$ ), and on the south side of the Altai Mountain region (desert-steppe). Thus, erosivity is the major driving force to cause dust outbreaks. The DOF at those stations was less than $10 \%$, resulting from infrequent strong winds with lower SWF values (figure not shown) of $<5 \%$ and $5-10 \%$ in the Taklimakan Desert and the Altai Mountain region, respectively. The DOF at the other stations was higher than $10 \%$, resulting from higher values of the DOR.

\section{b. Steppe region}

Erodibility, rather than erosivity, has a significant impact on dust occurrence in the Mongolian and Inner Mongolian steppes. In the Mongolian steppe, the summer precipitation or the annual maximum NDVI in the previous year is responsible for the yearto-year variations in the DOF. The connection between summer precipitation and the DOF in the following spring is bridged by soil moisture. The soil moisture anomaly, which depends on summer precipitation, is considered to act as a maintained memory through the freezing winter months to the spring, as reported by Shinoda and Nandintsetseg (2011). When the temperature decreases below $0^{\circ} \mathrm{C}$, the soil water anomaly is preserved by soil freezing. In the following April, the frozen soil melts as the temperature increases, providing a wet land surface condition that suppresses the dust outbreaks. As for the annual maximum NDVI, Kurosaki et al. (2011b) proposed a dead-leaf hypothesis for the Mongolian grasslands, which has been modeled by Nandintsetesg and Shinoda (2015). In this hypothesis, the summer vegetation anomaly, which depends on precipitation and soil moisture, remains into the next spring due to the coverage of dead leaves on the top of the soil moisture. The dead leaves decrease erodibility and reduce the occurrence of dust outbreaks.

On the other hand, an increasing trend in the spring NDVI reduces the occurrence of dust outbreaks in the Inner Mongolia steppe. The Chinese government's policy of deferring spring grazing in Inner Mongolia increased the spring vegetation cover and the grassland productivity (e.g., Ma et al. 2014), leading to low DOF values. Playing a similar role to the vegetation, the spring snow cover also reduces the DOF by suppressing wind erosion.

One exception is observed at Xilin-hot $\left(116.06^{\circ} \mathrm{E}, 43.95^{\circ} \mathrm{N}\right)$, where the DOF was controlled by erosivity. The reason for this exception is unclear.

\section{c. Loess Plateau}

In the desertified areas in the Loess Plateau, the occurrence of dust outbreaks is primarily controlled by the SWF or M. The stations, Otogo-qi $\left(107.97^{\circ} \mathrm{E}, 39.1^{\circ} \mathrm{N}\right)$, Yulin $\left(109.69^{\circ} \mathrm{E}, 38.23^{\circ} \mathrm{N}\right)$, and Jartai $\left(105.74^{\circ} \mathrm{E}, 39.78^{\circ} \mathrm{N}\right)$, are located in the region where aeolian desertification exhibited a reversing trend (that is, likely with restored vegetation), as illustrated by the map of Wang et al. (2008). Although the map indicates the condition of desertification in 2000, the trend in the annual maximum NDVI from 2000 to 2012 (see Fig. 2) at the stations around the Loess Plateau was less than $1 \%$. Thus, we consider that the condition of desertification is similar to that for the current decade. The annual maximum vegetation observed in the summer appeared to suppress dust outbreaks in the following spring at these stations. Spring vegetation expressed by NDVI in April also had a negative impact on dust outbreaks at Yulin. The natural vegetation at Yulin was from the southeast forest grassland to the northwest grassland (Wang et al. 2012). As one of the key regions of the Three-North Shelter Program, which was initiated in 1978 and was planned to be completed the project's goal around 2050, it has been suggested that the afforestation also increased the vegetation cover at Yulin (e.g., Liu et al. 2013).

In contrast, the other two stations, Yanchi $\left(107.39^{\circ} \mathrm{E}, 37.78^{\circ} \mathrm{N}\right)$ and Dongsheng $\left(109.97^{\circ} \mathrm{E}, 39.83^{\circ} \mathrm{N}\right)$, are located in the desertified (not reclaimed) areas in the map of Wang et al. (2008). The DOF at these two stations was controlled by erosivity.

Since the DOR might be controlled by multiple erodibility parameters, the significant factor was not identified at some stations by the simple linear regression analysis in the present analysis.

\section{Summary}

Contributions of erosivity and erodibility to dust emission differ substantially from region to region, depending on characteristics of land surface conditions. Kurosaki et al. (2011b) suggested that erosivity controls the DOF in the desert regions, while erodibility factors show a greater effect in other regions. The significant impact of erodibility parameters of precipitation, soil moisture, and above-ground biomass on variations in the DOF has been investigated at only one station in Mongolia by Kurosaki et al. (2011a). Their findings have been confirmed by the present study and furthermore the previous analysis was for the first time extended to a wider dust-producing area of East Asia.

In the present study, we investigated the characteristics of dust occurrence (DOF), erosivity (SWF) and erodibility (DOR, defined as the ratio of DOF to SWF) in East Asia during the period of 1999 to 2013. We presented a map of the controlling factor for dust outbreaks in East Asia by identifying the relative contributions of erosivity and various erodibility parameters to inter-annual variations in dust occurrence (DOF) on a station basis. The results are summarized as follows:

Erosivity was the major controlling factor for dust outbreaks at most stations in the Taklimakan Desert and on the north side of the Altai Mountain region. Erodibility, rather than erosivity, has a significant impact on dust outbreaks in the steppe regions. Lower precipitation or poor vegetation in the previous summer was connected to dusty springs in the Mongolian steppe. Moreover, vegetation and snow cover in spring suppressed dust outbreaks in the Inner Mongolian steppe. Anthropogenically restored vegetation in desertified areas reduced the occurrence of dust outbreaks in the Loess Plateau.

\section{Acknowledgements}

The present study is supported in part by Grants-in-Aid for Scientific Research from JSPS (Nos. 24340111 and 25220201), by the JSPS Core-to-Core Program (B. Asia-Africa Science Platforms), and by Budget Request of Tottori University, sponsored by special coordinate funds from the Ministry of Education, Culture, Sports, Science and Technology of the Japanese Government.

Edited by: T. Takemi

\section{References}

Abulaiti, A., R. Kimura, M. Shinoda, Y. Kurosaki, M. Mikami, M. Ishizuka, Y. Yamada, E. Nishihara, and B. Gantsetseg, 2014: An observational study of saltation and dust emission in a hotspot of Mongolia. Aeolian Res., 15, 169-176.

Aoki, I., Y. Kurosaki, R. Osada, T. Sato, and F. Kimura, 2005: Dust storms generated by mesoscale cold fronts in the Tarim Basin, Northwest China. Geophys. Res. Lett., 32, 6.

Ginoux, P., M. Chin, I. Tegen, J. M. Prospero, B. Holben, O. Dubovik, and S. J. Lin, 2001: Sources and distributions of dust aerosols simulated with the GOCART model. J. Geophys. Res. Atmos., 106, 20255-20273.

Hall, Dorothy K., G. A. R., and V. V. Salomonson, 2006: Updated monthly. MODIS/Terra Snow Cover Daily L3 Global 0.05Deg CMG. Version5., Boulder, Colorado USA: National 329 Snow and Ice Data Center.

Han, L., A. Tsunekawa, and M. Tsubo, 2011: Effect of frozen ground on dust outbreaks in spring on the eastern Mongolian Plateau. Geomorphology, 129, 412-416.

Ishizuka, M., M. Mikami, Y. Yamada, R. Kimura, Y. Kurosaki, D. Jugder, B. Gantsetseg, Y. Cheng, and M. Shinoda, 2012: 
Does ground surface soil aggregation affect transition of the wind speed threshold for saltation and dust emission? SOLA, 8, 129-132.

Kim, H. S., and K. Kai, 2007: Recent dust outbreaks in the Taklimakan desert and their relation to surface wind and land surface condition. SOLA, 3, 69-72.

Kimura, R., and M. Shinoda, 2010: Spatial distribution of threshold wind speeds for dust outbreaks in northeast Asia. Geomorphology, 114, 319-325.

Kurosaki, Y., and M. Mikami, 2003: Recent frequent dust events and their relation to surface wind in East Asia. Geophys. Res. Lett., 30, 1736.

Kurosaki, Y., and M. Mikami, 2005: Regional difference in the characteristic of dust event in East Asia: relationship among dust outbreak, surface wind, and land surface. J. Meteor. Soc. Japan, 83, 1-18.

Kurosaki, Y., and M. Mikami 2007: Threshold wind speed for dust emission in east Asia and its seasonal variations. J. Geophys. Res., 112, D17202.

Kurosaki, Y., M. Shinoda, M. Mikami, and B. Nandintsetseg, 2011a: Effects of soil and land surface conditions in summer on dust outbreaks in the following spring in a Mongolian grassland. SOLA, 7, 69-72.

Kurosaki, Y., M. Shinoda, and M. Mikami, 2011b: What caused a recent increase in dust outbreaks over East Asia? J. Geophys. Res., 38, L11702.

Lee, J. J., and C. H. Kim, 2012: Roles of surface wind, NDVI and snow cover in the recent changes in Asian dust storm occurrence frequency. Atmos. Environ., 59, 366-375.

Liu, L., H. Tang, P. Caccetta, E. A. Lehmann, Y. Hu, and X. Wu, 2013: Mapping afforestation and deforestation from 1974 to 2012 using Landsat time-series stacks in Yulin District, a key region of the Three-North Shelter region, China. Environ. Monit. Assess., 185, 9949-9965.

Liu, X., Z. Y. Yin, X. Zhang, and X. Yang, 2004: Analyses of the spring dust storm frequency of Northern China in relation to antecedent and concurrent wind, precipitation, vegetation, and soil moisture conditions. J. Geophys. Res., 109, D16210.

Ma, L., F. Yuan, H. Liang, and Y. Rong, 2014: The effects of grazing management strategies on the vegetation, diet quality, intake and performance of free grazing sheep. Livest. Sci., 161, 185-192.

Miller, R., and I. Tegen, 1998: Climate response to soil dust aerosols. J. Climate, 11, 3247-3267.

Natsagdorj, L., D. Jugder, and Y. Chung, 2003: Analysis of dust storms observed in Mongolia during 1937-1999. Atmos. Environ., 37, 1401-1411.

Nandintsetseg, B., and M. Shinoda, 2015: Land surface memory effects on dust emission in a Mongolian temperate grassland. J. Geophys. Res., 120, 414-427.

Qi, J., J. Chen, S. Wan., and L. Ai 2012: Understanding the coupled natural and human systems in Dryland East Asia. Environ. Res. Lett., 7, 015202.

Shinoda, M., J. Gillies, M. Mikami, and Y. Shao, 2011: Temperate grasslands as a dust source: Knowledge, uncertainties, and challenges. Aeolian Res., 3, 71-293.
Shinoda, M., and B. Nandintsetseg, 2011: Soil moisture and vegetation memories in a cold, arid climate. Glob. Planet. Change, 79, 110-117.

Takemi, T., and N. Seino, 2005: Dust storms and cyclone tracks over the arid regions in east Asia in spring. J. Geophys. Res., 110, D18S11, doi:10.1029/2004JD004698.

Tegen, I., and I. Fung, 1994: Modeling of mineral dust in the atmosphere: Sources, transport, and optical thickness. $J$. Geophys. Res., 99, 22897-22914.

Todd, M., D. Karam, C. Cavazos, C. Bouet, B. Heinold, J. Baldasano, G. Cautenet, I. Koren, C. Perez, F. Solmon, I. Tegen, P. Tulet, R. Washington, and A. Zakey, 2008: Quantifying uncertainty in estimates of mineral dust flux: An intercomparison of model performance over the Bodélé Depression, northern Chad. J. Geophys. Res., 113, D24107.

United Nations Environment Programme, 1997: World Atlas of Desertification. 2nd Ed., N. J. Middleton and D. S. G. Thomas, Eds., Edward Arnold, London.

Uno, I., Z. Wang, M. Chiba, Y. Chun, S. Gong, Y. Hara, E. Jung, S. S. Lee, M. Liu, M. Mikami, S. Music, S. Nickovic, S. Satake, Y. Shao, Z. Song, N. Sugimoto, T. Tanaka, and D. Westphal, 2006: Dust model intercomparison (DMIP) study over Asia: Overview. J. Geophys. Res., 111, D12213, doi:12210.11029/12005JD006575.

Wang, T., W. Wu, X. Xue, W. Zhang, Z. Han, and Q. Sun, 2003: Time-space evolution of desertification land in northern China. J. Desert Res., 23, 230-235 (in Chinese with English abstract).

Wang, T., J. G. Sun, H. Han, and C. Z. Yan, 2012: The relative role of climate change and human activities in the desertification process in Yulin region of northwest China. Environ. Monit. Assess., 184, 7165-7173.

Wang, S., J. Wang, Z. Zhou, and K. Shang, 2005: Regional characteristics of three kinds of dust storm events in China. Atmos. Environ., 39, 509-520.

Wang, X., J. Huang, M. Ji, and K. Higuchi, 2008: Variability of East Asia dust events and their long-term trend. Atmos. Environ., 42, 3156-3165.

Woodage, M., A. Slingo, S. Woodward, and R. Comer, 2010: UK HiGEM: Simulations of desert dust and biomass burning aerosols with a high-resolution atmospheric GCM. J. Climate, 23, 1636-1659.

World Meteorological Organization, 1995: Manual on Codes, International Codes, vol. I.1 (Annex II to WMO Technical Regulations), part A, Alphanumeric Codes. Geneva, Switzerland.

Xu, X., J. K. Levy, L. Zhaohui, and C. Hong, 2006: An investigation of sand-dust storm events and land surface characteristics in china using NOAA NDVI data. Glob. Planet. Change, 52, 182-196.

Zou, X. K., and P. M. Zhai, 2004: Relationship between vegetation coverage and spring dust storms over northern china. $J$. Geophys. Res., 109, D03104.

Manuscript received 22 April 2016, accepted 20 June 2016

SOLA: https://www.jstage.jst.go.jp/browse/sola/ 